\title{
The synoptic-dynamics of summertime heatwaves in the Sydney area (Australia)
}

\author{
Tess Parker $^{\mathrm{A}, \mathrm{D}}$, Julian Quinting ${ }^{\mathrm{A}, \mathrm{B}}$ and Michael Reeder ${ }^{\mathrm{A}, \mathrm{C}}$ \\ A School of Earth, Atmosphere and Environment, Monash University, Building 28, 9 Rainforest \\ Walk, Clayton, Vic. 3800, Australia. \\ ${ }^{B}$ Institute of Meteorology and Climate Research (IMK-TRO), Karlsruhe Institute of Technology, \\ Karlsruhe, Germany. \\ ${ }^{C}$ ARC Centre of Excellence for Climate Extremes, Monash University, Clayton, Vic., Australia. \\ ${ }^{D}$ Corresponding author. Email: tess.parker@monash.edu
}

\begin{abstract}
Motivated by the record-breaking heatwaves of early 2017, the synoptic structure and evolution of summer (December-February) heatwaves in the Sydney area is investigated through composite and trajectory analyses. In the upper troposphere, the main features of the composite structure are an isolated upper-tropospheric anticyclonic potential vorticity (PV) anomaly to the south-east of Australia and cyclonic anomalies to the east and south. Back trajectories starting from within the upper-tropospheric anticyclonic PV anomaly on the first day of the heatwave fall into two groups: those that are diabatically cooled in the final $72 \mathrm{~h}$ and those that are diabatically heated. Those that are cooled come predominantly from the upstream middle troposphere over the Indian Ocean. The change in the potential temperature of these parcels is less than $3 \mathrm{~K}$, and so their motion is effectively adiabatic. In contrast, those parcels that are heated in the final $72 \mathrm{~h}$ are drawn predominantly from the lower half of the troposphere over the south-western part of the continent. As they ascended, their potential temperature increases by $10 \mathrm{~K}$ in the mean due to latent heating. At low-levels, the main features of the composite are an anticyclone centred in the Tasman Sea, a broad low over the Southern Ocean and associated anomalous warm northwesterlies over the Sydney area. Five days prior to the heatwave, air parcels that become part of the near surface air mass are located predominantly offshore to the east and south of the continent. The anomalously high surface temperatures can be explained by adiabatic compression and surface sensible heating. For the next $48 \mathrm{~h}$, the air parcels subside and their potential temperature changes little, whereas their temperature increases by around $15 \mathrm{~K}$ through adiabatic compression. In the final $72 \mathrm{~h}$, as the parcels approach the surface and are entrained into the boundary layer, the potential temperature and temperature both increase by $5 \mathrm{~K}$, presumably through surface sensible heating. The record-breaking heatwaves of January and February 2017 are found to be very representative of previous heatwaves in the Sydney area, and in the mean they are synoptically very similar to heatwaves in Victoria, although dynamically there are differences.
\end{abstract}

Received 19 August 2018, accepted 5 April 2019, published online 11 June 2020

\section{Introduction}

Summer heatwaves cause more deaths in Australia than any other natural hazard (Coates et al. 2014). Over the past few decades, their frequency has increased (Perkins and Alexander 2013), and climate projections show that their intensity, frequency and duration will increase further (e.g. Alexander and Arblaster 2009; Cowan et al. 2014). In early 2017, a series of record-breaking heatwaves affected southern Queensland, New South Wales (NSW) and parts of northern Victoria, during which Sydney and Brisbane recorded their highest mean monthly temperatures on record (Bureau of Meteorology $2017 a$ ). Although the duration and intensity of the 2017 heatwave was comparable to the January-February 2009 heatwave in south-eastern Australia, it was located further north leading to new temperature records in central NSW. These record breaking conditions raise questions concerning the physical mechanisms behind heatwaves in NSW in general, and how they differ from heatwaves in Victoria and elsewhere.

Heatwaves in Victoria have been more studied than those elsewhere in the country. They are associated with mid- to upper-tropospheric quasi-stationary anticyclonic flow anomalies centred over the south-east of Australia (e.g. Parker et al. 2014; Purich et al. 2014). These anticyclonic anomalies evolve from midlatitude Rossby waves that grow and break anticyclonically over southern Australia. The upper-tropospheric anticyclones are strongly modified by diabatic processes (Quinting and Reeder 2017). Air masses located over Australia prior to the heatwave ascend over a low-level midlatitude baroclinic zone ahead of an upper-tropospheric trough, and this ascent is associated with anomalously high rainfall over the Great Australian Bight (Parker et al. 2014). Diabatic heating and its associated cross-isentropic flow transports low-potential 
vorticity (PV) air into regions that are climatologically located in the lower stratosphere. In this way, the diabatic processes contribute to the subsequent amplification of the upper-tropospheric anticyclonic anomaly. In addition, diabatically enhanced divergent outflow advects anomalously anticyclonic PV air poleward, further amplifying the anticyclone (Parker et al. 2013). The upper-tropospheric anticyclone is accompanied by a surface anticyclone centred east of the continent over the Tasman Sea, and this anticyclone plays a major role in producing anomalously high temperatures at the surface in Victoria. Subsidence within this high-pressure area produces warming through adiabatic compression, as isentropes are deflected downwards below the upper-level anticylonic anomaly (Quinting and Reeder 2017). As this subsiding air reaches the lower troposphere, it is advected southward on the western flank of the anticyclone and over the Australian continent. Here, the air is heated diabatically in the boundary layer through surface sensible heat fluxes. Thus, it is the combination of adiabatic warming in the anticyclone over the Tasman Sea and diabatic heating at low levels over the Australian continent that leads to the anomalously high temperatures in Victoria.

A recent study by Quinting et al. (2018) examined the synoptic structure and evolution of summer heatwaves in the Australian subtropics, using the Brisbane region of Queensland as an example. Like Quinting and Reeder (2017), the study identified adiabatic compression during subsidence of air parcels, and surface sensible heating in the boundary layer during horizontal advection, as the two most important processes by which the surface temperature is elevated. Focusing on heatwaves in which diabatic effects play the more important role, called strongly diabatic cases, and those in which adiabatic effects are more important, called weakly diabatic cases, revealed that the differing synoptic structures in each case leads to geographically distinct trajectories for air parcels that join the near-surface air mass during a heatwave. This results in different thermodynamic histories for these air parcels. In contrast to heatwaves over south-eastern Australia, which are associated with strong uppertropospheric anticyclonic circulations (Parker et al. 2013; Quinting and Reeder 2017), strongly diabatic heatwaves in the Brisbane region are characterised by a midlatitude cyclonic $\mathrm{PV}$ anomaly to the south-east of the continent with a horseshoe of weaker anticyclonic PV on the eastern flank. Weakly diabatic heatwaves, on the other hand, show an upper-tropospheric anticyclonic PV anomaly close to the Brisbane region, with regions of cyclonic PV to the south and east (Quinting et al. 2018). For the first time, one of the defining features of heatwaves has been shown to be an upper-tropospheric cyclonic circulation, rather than the anticyclonic circulation reported so far in the literature for heatwaves in all parts of the world.

Although recent studies have led to an improvement in the understanding of the dynamics of heatwaves in Victoria and the Brisbane region on the synoptic scale, the dynamical processes responsible for heatwaves in NSW have not been investigated in detail. Statistically significant relationships between the El Niño-Southern Oscillation and heatwaves in NSW have been found (Perkins et al. 2015). In particular, heatwaves in NSW tend to be more frequent, longer and more intense under El Niño phases of the El Niño-Southern Oscillation. In addition, locally reduced soil moisture appears to favour heatwave conditions in that region, presumably through enhanced sensible heat fluxes (Perkins et al. 2015; Herold et al. 2016). However, low soil moisture is not a sufficient condition for the development of heatwaves (Herold et al. 2016), pointing to the importance of other mechanisms. Indeed the precise role of soil moisture in heatwaves in the region remains unclear. For example, in simulations of the Black Saturday heatwave, increasing the soil moisture increased the maximum temperatures over Victoria (Kala et al. 2015). Gibson et al. (2017) examined the nearsurface synoptic pattern associated with heatwaves in southeastern Australia (defined approximately as the region east of the longitude of Melbourne and from the latitudes of Brisbane to south of Victoria). Using self-organising maps, they showed that the characteristic mean sea-level pressure (MSLP) comprises an anticyclone in the Tasman Sea extending inland over southeastern Australia and a broad trough to the west of that. This pattern is essentially the same as that found for Victorian heatwaves (see, e.g. Parker et al. 2014).

The present study aims to clarify the synoptic-dynamical structure and evolution of heatwaves in NSW. In particular, it seeks to answer the questions: how dynamically different are heatwaves in NSW from those in Victoria and how representative were the heatwaves of 2017 of previous heatwaves in NSW? As well as being of importance in their own right, the answers to these questions are essential prerequisites to understanding the changes anticipated in a warmer world and to properly evaluating climate model projections.

\section{Methodology and data}

\subsection{Definition of heatwaves}

Heatwaves are defined using the Australian Climate Observations Reference Network - Surface Air Temperature (ACORNSAT; http://www.bom.gov.au/climate/change/acorn-sat/, accessed 11 May 2020) data set. This homogenised long-term data set comprises 112 locations chosen to maximise both the length of the record and the spatial coverage across the Australian continent. Daily maximum temperatures during December-February (DJF) 1989-2009 for the nine observation locations within a $500 \times 500 \mathrm{~km}$ box centred on Sydney, NSW (Fig. 1) are obtained from the ACORN-SAT temperature record. This box defines the Sydney area. A heatwave is then defined as any period of at least 3 consecutive days for which the daily maximum temperature at one or more of these locations equals or exceeds the 90th percentile maximum at that location for that month. This method identifies 49 heatwaves of varying length in the Sydney area for the 21-year period of interest. The definition of a heatwave used here is slightly simpler than that in Parker et al. (2014) as it omits an additional condition on the overnight temperature. Using the simpler definition makes virtually no difference to the results, which is an important finding in itself as it means that high overnight temperatures are part of synoptic-dynamics of heatwaves. The significance of this point will become clearer later when the precipitable water is examined.

\subsection{Composite analysis}

Data for the DJF summer season from January 1989 to December 2009 are extracted from the Interim European Centre 


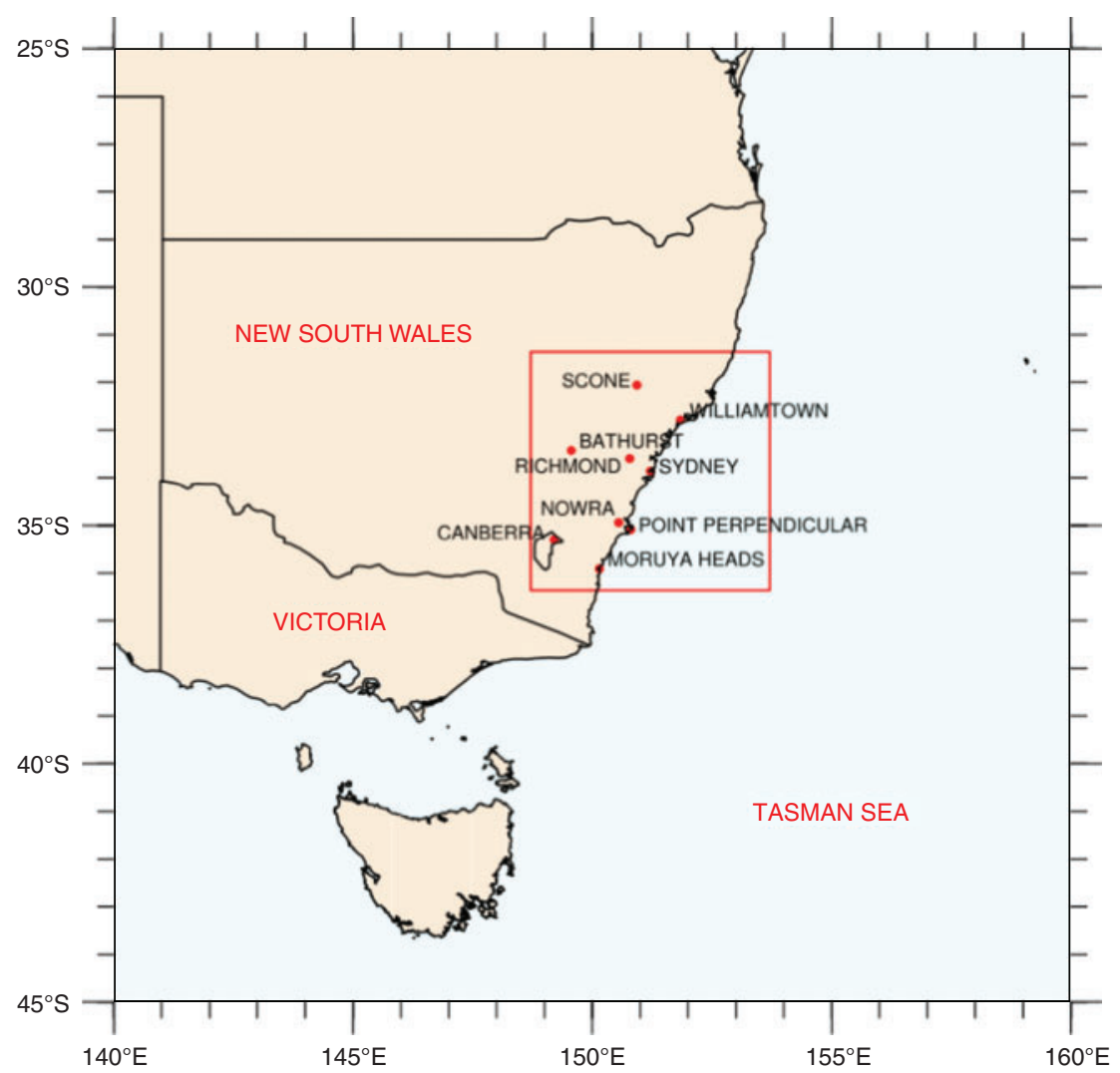

Fig. 1 Map showing the locations of observation sites within a $500 \times 500 \mathrm{~km}$ box centred on Sydney, New South Wales. This box defines the Sydney area.

for Medium-Range Weather Forecasts Reanalysis (ERAInterim, herein ERAI; Dee et al. 2011). Composite anomalies are calculated as the deviation from the seasonal mean for all DJF months from 1989 to 2009. Precipitation data for the period from 1 October 1996 to date are available from the Global Precipitation Climatology Project (GPCP) (Huffman et al. 2001). Data for DJF from 1996 to 2009 are extracted from the GPCP One-Degree Daily Data Set (1DD data set) Version 1.2 from the Mesoscale Atmospheric Processes Laboratory, National Aeronautics and Space Administration Goddard Space Flight Center. Composite rainfall anomalies are taken as the departure from the day-of-the-year mean calculated from the daily rainfall data for 1996-2009. Composites of various quantities are also calculated from ERAI and GPCP data for 9-12 February 2017, the period of the recent intense heatwave in the Sydney area.

\subsection{Trajectory analysis}

For the same period as the composite analysis, two sets of 10-day backward trajectories are used to analyse the characteristics of the air masses that combine to form Sydney heatwaves. These trajectories are computed from the threedimensional wind field from the ERAI reanalyses available at 60 model levels and on a regular $0.75^{\circ}$ longitude-latitude grid. The starting time of the trajectories is defined as $0 \mathrm{~h}$. The backward trajectories are computed with the Lagrangian analysis tool (LAGRANTO; Sprenger and Wernli 2015) and the evolution of certain quantities along these trajectories is calculated also. These traced quantities are the specific humidity, PV, PV anomalies relative to the monthly climatology, temperature and potential temperature. Changes in the potential temperature along the trajectories are attributed to diabatic processes. Since the trajectories start from a regular longitude-latitude grid, all averages are weighted by the square-root of the cosine of latitude of the trajectory at the starting time.

Following Pfahl et al. (2015), the first set of 10-day backward trajectories is designed to analyse the thermodynamic history and geographical origin of the constituent air masses comprising the upper-tropospheric PV anomalies. Recall that anticyclonic $\mathrm{PV}$ is positive in the southern hemisphere and that the stratosphere is characterised by PV that is more negative (more cyclonic) than -2 PVU. The trajectories start from grid points lying between 500 and $150 \mathrm{hPa}$ at $50-\mathrm{hPa}$ intervals at which (1) the vertically integrated PV anomaly exceeds (is more anticyclonic than) 1 PVU relative to the monthly climatology (where 1 $\mathrm{PVU}=10^{-6} \mathrm{~K} \mathrm{~m}^{2} \mathrm{~kg}^{-1} \mathrm{~s}^{-1}$ ) and (2) the instantaneous PV exceeds -1 PVU, so as to exclude grid points in the stratosphere from the analysis.

To analyse the thermodynamic history and geographical origin of air masses close to the surface, a second set of trajectories is computed. These trajectories are started from all grid points 10,30 and $50 \mathrm{hPa}$ above the surface in the 
Sydney area. Starting the trajectories from different heights accounts for variations in the planetary boundary layer height (Bieli et al. 2015).

\section{Sydney-area heatwaves: 9-12 February 2017}

As mentioned in Section 1, this investigation is motivated by the severe heatwaves of early 2017. Using the definition from Section 2.1, there were four heatwaves in the Sydney area comprising 16 heatwave days. The dates of these heatwaves are 9-13 January, 29 January-1 February, 4-6 February and 9-12 February 2017. Although the synoptic structure of each of these heatwaves is similar, they vary in detail, of course. The fourth was the most severe and a brief discussion of its structure will set the scene for the later climatological investigation of the heatwaves in the Sydney area (Section 4). However, before discussing the synoptic structure, the 9-12 February heatwave is placed in an historical context by listing a few indicative records set at the observation sites in the Sydney area (Fig. 1). The records are taken from Bureau of Meteorology (2017a).

- A record February temperature for Sydney Airport, $42.9^{\circ} \mathrm{C}$, was set on 10 February.

- On 11 February at Richmond, the maximum temperature was $47.0^{\circ} \mathrm{C}$ and set the record for the highest February temperature recorded at any of the sites in the Sydney basin, exceeding the 90th percentile February maximum for this location by $12.4^{\circ} \mathrm{C}$.

- At Williamtown, a record for any month at that site of $45.5^{\circ} \mathrm{C}$ was set on 11 February.

- The temperature at Scone on 12 February was $46.5^{\circ} \mathrm{C}$, which set a record for any month at that site.

The composite mean PV anomaly on the $350 \mathrm{~K}$ surface for the 9-12 February heatwave is shown in Fig. $2 a$. There are two anticyclonic PV anomalies, one centred over the Tasman Sea and the other lying just poleward of the south-western region of Western Australia. The second anticyclonic anomaly is associated with the heavy rainfall over Western Australia (Bureau of Meteorology 2017b) and is atypical of the synoptic pattern for Sydney-area heatwaves (see Section 4). A zonally-oriented cyclonic anomaly lies south of the continent, with other cyclonic anomalies lying to the east of New Zealand, equatorward of the eastern anticyclonic anomaly and westward of the western anticyclonic anomaly.

A vertical cross section along the longitude $152.5^{\circ} \mathrm{E}$ is plotted in Fig. $2 b$. The cross section cuts through the eastern anticyclonic anomaly close to Sydney $\left(151.2^{\circ} \mathrm{E}\right.$ and $\left.33.9^{\circ} \mathrm{S}\right)$ and through the cyclonic anomaly south of the continent. These anomalies are strongest in the stratosphere and are connected by a jump in the tropopause of about $7 \mathrm{~km}$. The anticylonic anomaly is associated with easterlies on its equatorward side and westerlies on its poleward side, with this circulation extending to the surface. Likewise, the cyclonic anomaly is associated with deep westerlies on its equatorward side and deep easterlies on its poleward side. The westerlies are enhanced throughout the depth of the atmosphere in the region of the tropopause jump, strengthening the jet stream at about $45^{\circ} \mathrm{S}$ centred on $12-\mathrm{km}$ altitude (Fig. 2c).
The composite mean MSLP for 9-12 February is characterised by a very weak anticyclone over the Tasman Sea and a well-defined anticyclone to the west and south-west of the continent (Fig. 3a). These two anticyclonic regions are separated by a broad weak trough in the south-eastern corner of the continent connected to a low far to the south. The weakness of the anticyclone over the Tasman Sea can be judged from the MSLP anomaly pattern, which shows that the pressure there is lower than the climatological mean (Fig. 3b). The 850-hPa temperature shows that much of the central and eastern parts of the continent is anomalously warm with the maximum anomaly centred on the Sydney area (Fig. 3c). The anomalously low pressure to the south-east of the continent directs anomalous westerlies across the Sydney area (Fig. 3d).

The vertical motion in pressure coordinates is $\omega$, which is defined as the Lagrangian time rate of change of pressure. Positive 500-hPa $\omega$ (subsidence) is roughly colocated with the weak ridge in the Tasman Sea and the high pressure anomaly to the south-west of Australia (Fig. 3e). There is a wedge of negative $500-\mathrm{hPa}$ vertical motion (ascent) anchored to the south-eastern-most corner of the continent and extending to the south-east; this wedge of ascent marks the warm conveyor belt of the extratropical low and associated front (Fig. $3 d, c$ ). There is ascent over south-west Western Australia, the Top End and the South Pacific associated with the heavy rainfall there (Fig. 3f).

A ribbon of high precipitable water anomaly extends from the south Pacific, across the Australian tropics before circling around the western and southern parts of the continent (Fig. $3 g$ ). The anomaly is of order $5 \mathrm{~kg} \mathrm{~m}^{-2}$, which is roughly $20 \%$ of the climatological mean in the Sydney area. Although the precipitable water is high, the $1000-\mathrm{hPa}$ relative humidity anomaly is negative over the eastern part of the continent (Fig. $3 h$ ) where the temperature anomaly is positive (Fig. 3c). Likewise, the relative humidity is high over the western part of the continent where the temperature anomaly is negative.

\section{Composite of all heatwaves in the Sydney area during summer}

Composites are constructed for all heatwave days in the Sydney area in DJF from January 1989 to December 2009. For the ERAI data set, this consists of 209 days, whereas for the GPCP rainfall composites precipitation data are available for a total of 156 heatwave days.

Although not shown, heatwaves in the Sydney area are preceded by the development of a Rossby wave train over the southern Indian Ocean that propagates towards the Australian continent and is refracted towards the equator (Parker et al. 2014; O'Brien and Reeder 2017). The 350-K PV anomalies, which are one way of characterising the wave train, evolve in a qualitatively similar manner to those analysed during heatwaves in Victoria (see figure 3 in Parker et al. 2014).

A composite of the 350-K PV anomalies for all Sydney-area heatwave days (Fig. 4a) shows an upper tropospheric anticyclonic anomaly to the south-east of Australia, flanked by cyclonic anomalies to the east and south. The 350-K PV anomaly pattern is qualitatively similar to those during 




(b)
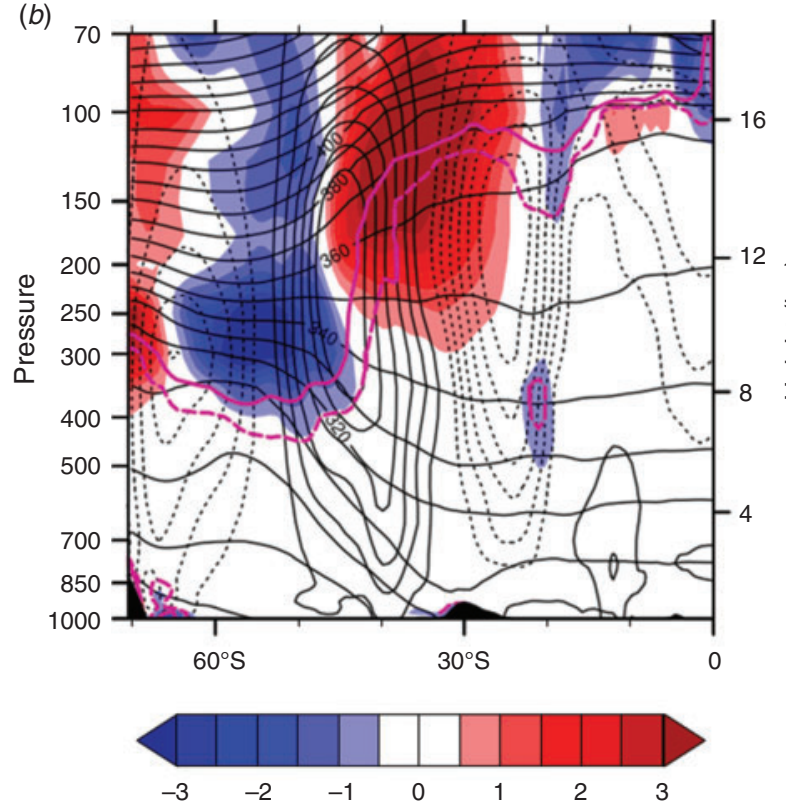

(c)

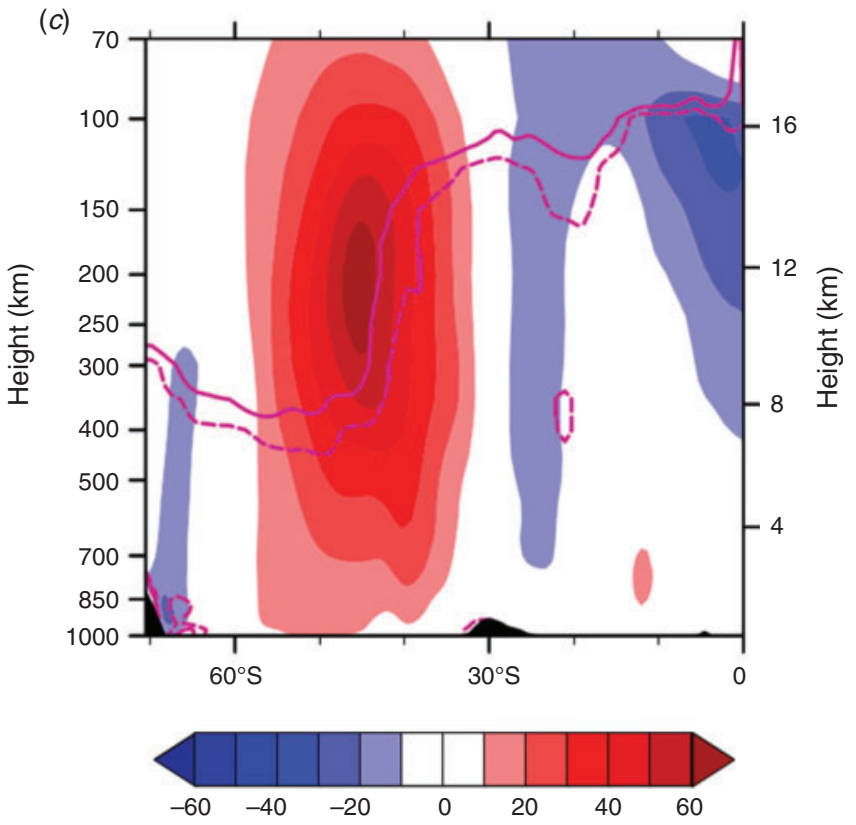

Fig. 2 (a) Composite mean 350-K PV anomaly for all heatwave days: 9-12 February 2017. PV anomalies (PVU) are shaded according to the colour bar. The solid (dashed) black line indicates the $-2 \mathrm{PVU}(-1 \mathrm{PVU})$ contour, and the thin black line denotes the $152.5^{\circ} \mathrm{E}$ longitude of the vertical cross section in the next panels. (b) Mean vertical cross section at $152.5^{\circ}$ E longitude for all Sydney-area heatwave days 9-12 February 2017 for PV anomalies (PVU) shaded as per the colour bar. The zonal wind anomalies are indicated by the black contour lines at $5 \mathrm{~m} \mathrm{~s}^{-1}$ intervals, with negative anomalies dashed. The solid (dashed) magenta line indicates the -2 PVU ( -1 PVU) contour. The left vertical scale is log of pressure (hPa) and right is height $(\mathrm{km})$; horizontal scale is latitude. Isentropes are indicated by the labelled black horizontal contour lines as 10-K intervals. (c) Mean vertical cross section as for $(b)$, but for mean zonal winds, shaded as per the colour bar. The solid black contour at the surface represents the approximate surface topography. PV, potential vorticity.

heatwaves in Victoria (see figure 3 in Parker et al. 2014), the main differences being that in the NSW case the amplitude of the anomalies is weaker and the anticyclonic anomalies are displaced around $1000 \mathrm{~km}$ north-east. In contrast, the composite
350-K PV anomalies for all Brisbane-area heatwave days is characterised by an upper tropospheric cyclonic anomaly to the south-east of Australia, with an anticyclonic anomaly to the north (Quinting et al. 2018). The composite anomaly pattern is 

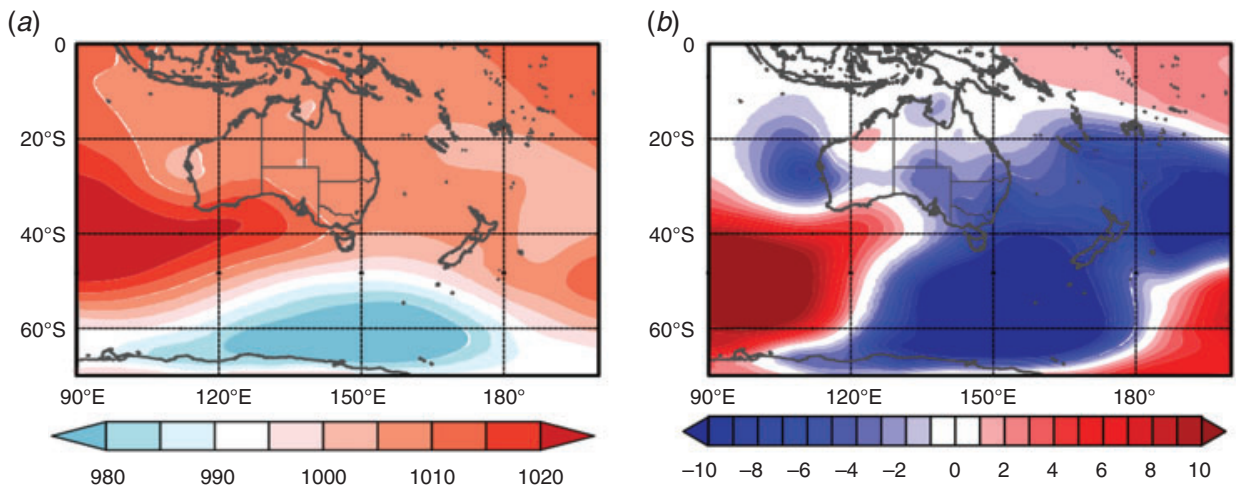

(c)
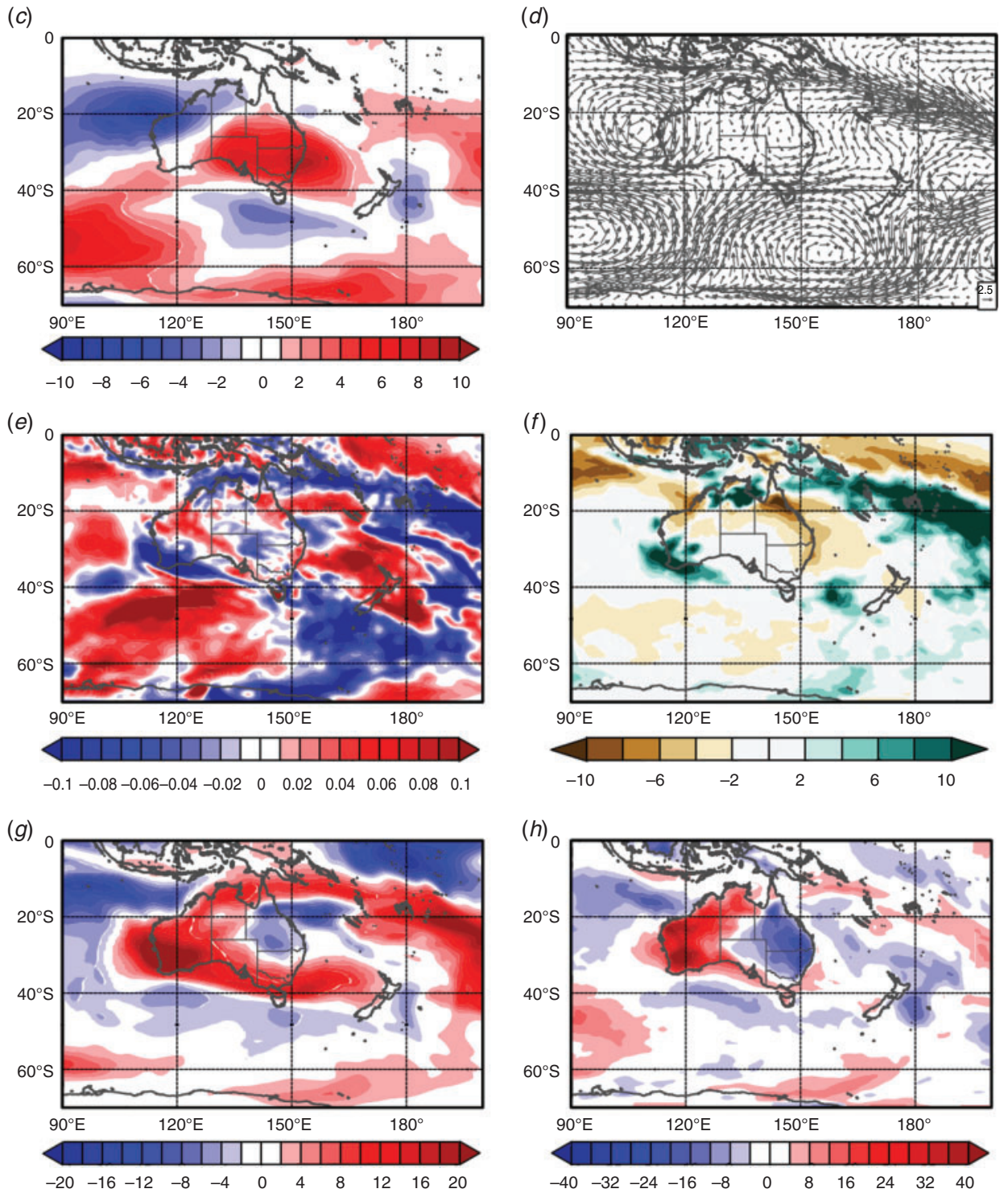

Fig. 3 Composite mean for all heatwave days 9-12 February 2017. (a) Mean sea-level pressure (MSLP) (hPa). (b) MSLP anomalies (hPa). (c) 850-hPa temperature anomalies (K). (d) 850-hPa wind speed anomalies and wind vectors (reference wind vector at bottom right of the panel). (e) 500-hPa vertical motion $\omega$ anomalies $\left(\mathrm{Pa} \mathrm{s}^{-1}\right)$. (f) Global Precipitation Climatology Project (GPCP) precipitation anomalies $\left(\mathrm{mm} \mathrm{day}^{-1}\right)$. $(g)$ Precipitable water anomalies $\left(\mathrm{kg} \mathrm{m}^{-2}\right)$. (h) 1000-hPa relative humidity anomalies (\%). 


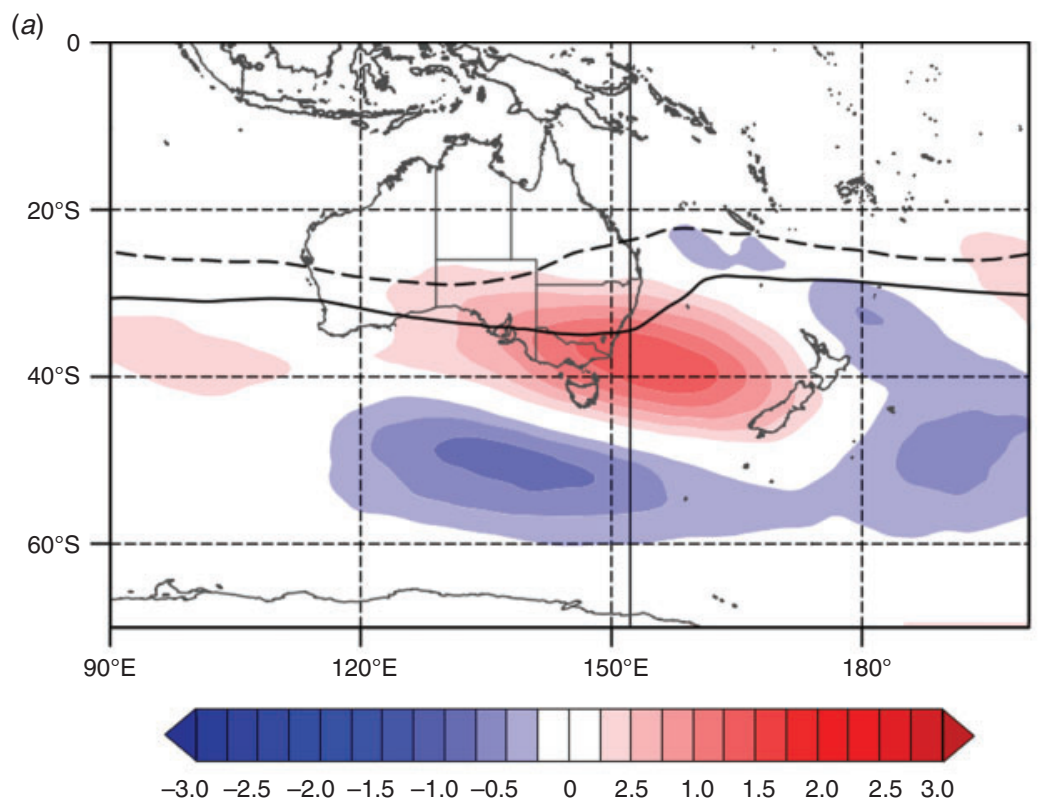

(b)
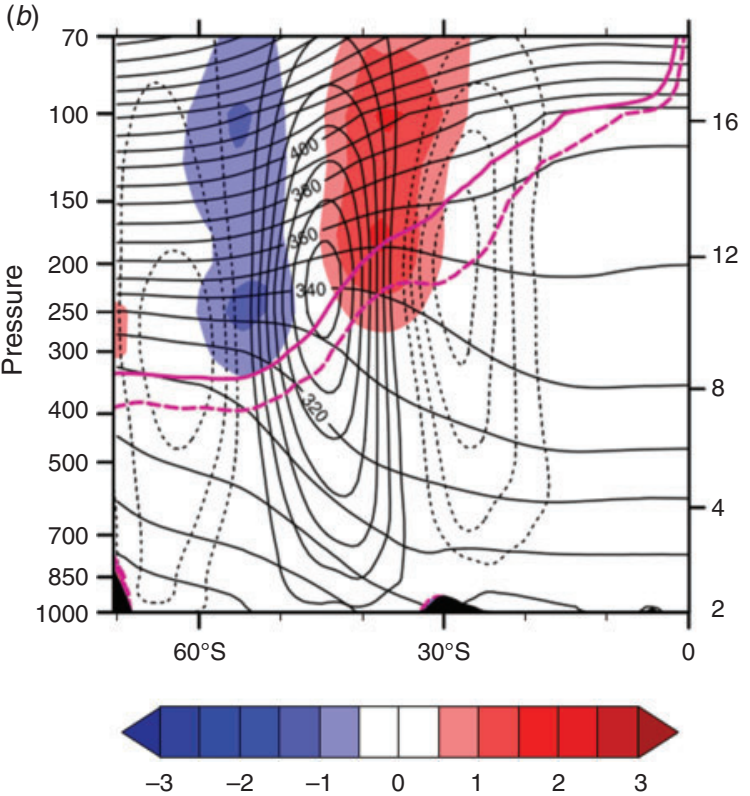

(c)

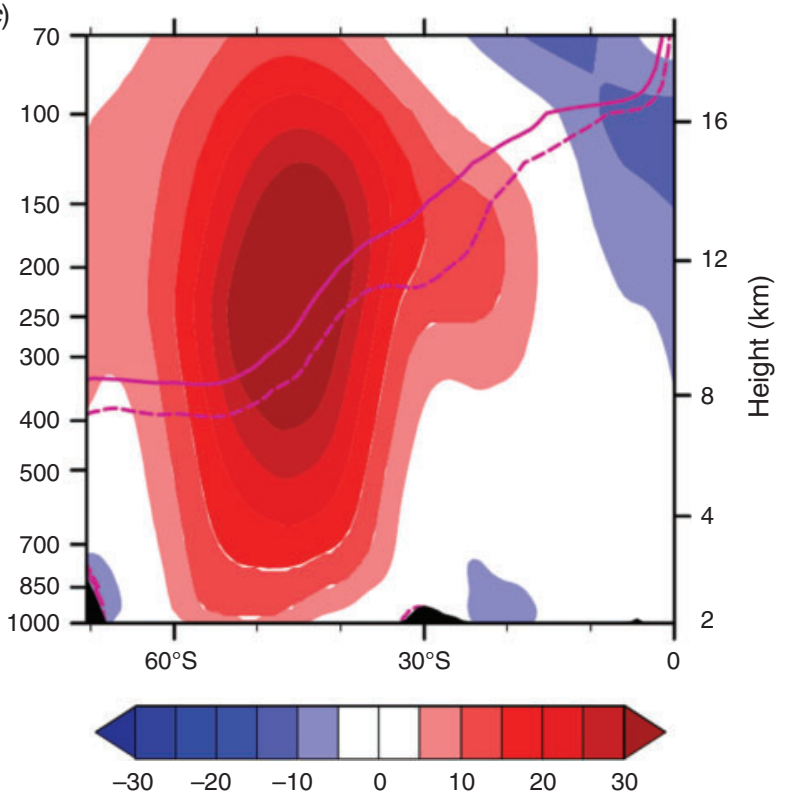

Fig. 4 (a) Composite mean 350-K PV anomaly for all Sydney-area heatwave days. PV anomalies (PVU) are shaded according to the colour bar. The solid (dashed) black line indicates the -2 PVU ( -1 PVU) contour, and the thin black line denotes the $152.5^{\circ} \mathrm{E}$ longitude of the vertical cross section in the next panels. (b) Mean vertical cross section at $152.5^{\circ} \mathrm{E}$ longitude for all Sydney-area heatwave days for PV anomalies (PVU) shaded as per the colour bar. The zonal wind anomalies are indicated by the black contour lines at $2 \mathrm{~m} \mathrm{~s}^{-1}$ intervals, with negative anomalies dashed. The solid (dashed) magenta line indicates the $-2 \mathrm{PVU}(-1 \mathrm{PVU})$ contour. The left vertical scale is log of pressure (hPa) and right is height (km); horizontal scale is latitude. Isentropes are indicated by the labelled black horizontal contour lines as $10 \mathrm{~K}$ intervals. $(c)$ Mean vertical cross section as for $(b)$, but for mean zonal winds, shaded as per the colour bar. The solid black contour at the surface represents the approximate surface topography. PV, potential vorticity.

also similar to that for the 9-12 February heatwave (Fig. 2a), the main differences in this case being that both the anticyclonic and cyclonic anomalies are larger than the composite mean of all heatwaves, and there is a second anticyclonic maximum southwest of the continent presumably associated with the divergent outflow above the diabatic heating there.
The deformation of the composite -2 PVU contour (or dynamical tropopause) in Fig. 4 indicates the transport of anomalously low (cyclonic) PV air equatorward and anomalously high (anticyclonic) PV air poleward towards the southeast of the Australian continent, resulting in the formation of the upper tropospheric anticyclone and flanking troughs. The 
-2 PVU contour, however, does not completely overturn, which is the hallmark of Rossby wave breaking (McIntyre and Palmer 1983, 1984; Song et al. 2011) and a common characteristic of heatwaves in Victoria even in the composite mean (see figure 3 of Parker et al. 2014). The -2 PVU contour does not completely overturn in the 9-12 February heatwave (Fig. 2a) either.

A vertical cross section at $152.5^{\circ} \mathrm{E}$ longitude (Fig. 4b), approximately through the centre of the anticyclonic PV anomaly (as marked in Fig. 4a), shows the composite PV anomalies and winds for all heatwave days. The PV anomalies are most pronounced in the stratosphere. Although the magnitude of the anomalies are weaker than those during heatwaves in Victoria, the zonal wind anomalies show maximum wind speeds of comparable strength between 200 and $250 \mathrm{hPa}$ (see figure 5 in Parker et al. 2014). The westerlies are enhanced throughout the depth of atmosphere between 40 and $60^{\circ} \mathrm{S}$ centred on 12-km altitude (Fig. 4c). In line with the PV-thinking framework introduced by Hoskins et al. (1985), the isentropes are deflected downwards beneath the anticyclonic anomaly but deflected upwards beneath the cyclonic anomaly. The downward deflection beneath the anticyclone is indicative of adiabatic compression and warming, which will be examined further in Section 2.3. Although the amplitude is greater, the equivalent cross section through the 9-12 February heatwave (Fig. 2b) is structurally similar to the composite mean of all heatwaves (Fig. 4b).

The composite MSLP comprises a broad cyclone over the Southern Ocean, anticyclones to the east and west of the continent with a ridge in the Great Australian Bight and a heat low in the north-western and central part of the continent that extends to the south-eastern corner (Fig. 5a), much like the 9-12 February heatwave (Fig. $3 a$ ). In contrast to the mean conditions during heatwaves in Victoria (see Parker et al. 2014), the extratropical low to the south of the continent is deeper and more extensive, whereas the ridge to the east is weaker. Heatwaves in the Sydney area are associated with anomalously low pressure over the south-eastern part of the continent and over the Southern Ocean, and weak anomalously high pressure over the northern part of the Tasman Sea and close to the west coast of the continent (Fig. 5b). During heatwaves in the Brisbane region (Quinting et al. 2018), there is a broad region of anomalously low pressure centred to the east of Tasmania, extending zonally to the south of the continent and northwards over the eastern part of the country and adjoining ocean.

The mean $850-\mathrm{hPa}$ wind anomalies for all Sydney-area heatwave days (Fig. $5 d$ ) include an anticyclonic circulation over the east coast of Australia, centred in the Tasman Sea between NSW and New Zealand. A large region of anomalously low MSLP to the south of the continent and a smaller region of high pressure to the east combine to form a northwestery flow over NSW (Fig. 5d). Anomalously high surface temperatures over $\mathrm{NSW}$, which define the heatwaves, are reflected in the $850-\mathrm{hPa}$ temperature anomalies (Fig. $5 c$ ). Higher temperatures extend in a broad band across the south-east of Australia, tilted from north-west to south-east and aligning with the north-westerly flow from the interior seen in the wind anomalies. The origin of this warmer air mass is investigated further in Section 5. The winds over tropical northern Australia are anomalously westerly, with a cyclonic circulation over the north-west of the continent consistent with an active phase of the Australian monsoon. The mean winds to the south of Australia are strongly westerly between 40 and $60^{\circ} \mathrm{S}$ to the south-west of the continent, with reduced wind speeds to the south-east.

At $500 \mathrm{hPa}$, there is subsidence above both of the surface anticyclones (Fig. 5e). A north-west-south-east oriented band of ascent lies along the trough axis over the continent (Fig. 5e), extending southward on the eastern side of the low pressure anomaly (Fig. 5b). This band lies between the maxima and minima of the $850-\mathrm{hPa}$ temperature anomalies (Fig. $5 c$ ) and forms the warm conveyor belt for the composite extratropical low. Although the pattern of vertical motion is noisier, the essential elements are the same in the 9-12 February heatwave (Fig. 3e).

The anomalously westerly flow in the tropics over northwestern Australia is consistent with enhanced rainfall over the north of the continent, as shown by the precipitation anomalies in Fig. 5f. The flow from the interior over the east coast and the area of mean descent at approximately $30^{\circ} \mathrm{S}$ are associated with anomalously low rainfall, and the regions of ascent ahead of the upper-tropospheric troughs to the south-east and north-east of the continent with enhanced rainfall. Precipitation over the Indian Ocean between approximately 10 and $20^{\circ} \mathrm{S}$ is reduced, indicating that the convection related to the Madden Julian Oscillation (MJO) is unlikely to be of importance for heatwaves in the Sydney area, and this is evident in an analysis of the conditional probability of heatwave days during the various phases of the MJO (not shown). This contrasts with heatwaves in Victoria, where the conditional probability is highest during MJO phases 3-6 when convection over northern Australia and the Maritime Continent is enhanced (Parker et al. 2014). Of the fields discussed, the precipitation anomalies for the 9-12 February heatwave (Fig. $3 e$ ) show the least agreement with the composite mean for the all heatwaves (Fig. 5f). In broad terms, both show enhanced rainfall over the Top End, reduced rainfall in the western parts of the Maritime continent and reduced precipitation over the east coast. However, there was very heavy rainfall over Western Australia during the 9-12 February heatwave (Bureau of Meteorology 2017b), which is reflected in Fig. $3 f$.

The precipitable water and $1000-\mathrm{hPa}$ relative humidity are plotted in Fig. $5 g$ and $h$. The precipitable water is high over most of the continent and extends south-eastward over the Sydney area into the southern part of the Tasman Sea. Presumably the increased water vapour enhances the downward long wave radiation, increasing the surface temperature both during the day and night. Near the surface, however, the relative humidity anomaly in the Sydney region is negative because of the increased temperature. The patterns of precipitable water and $1000-\mathrm{hPa}$ relative humidity for the 9-12 February heatwave (Fig. $3 g$ and $h$ ) are highly consistent with the composite mean for all heatwaves.

\section{Trajectories}

Back trajectories starting from within the upper-tropospheric anticyclonic PV anomaly between 500 and $150 \mathrm{hPa}$ (as outlined 

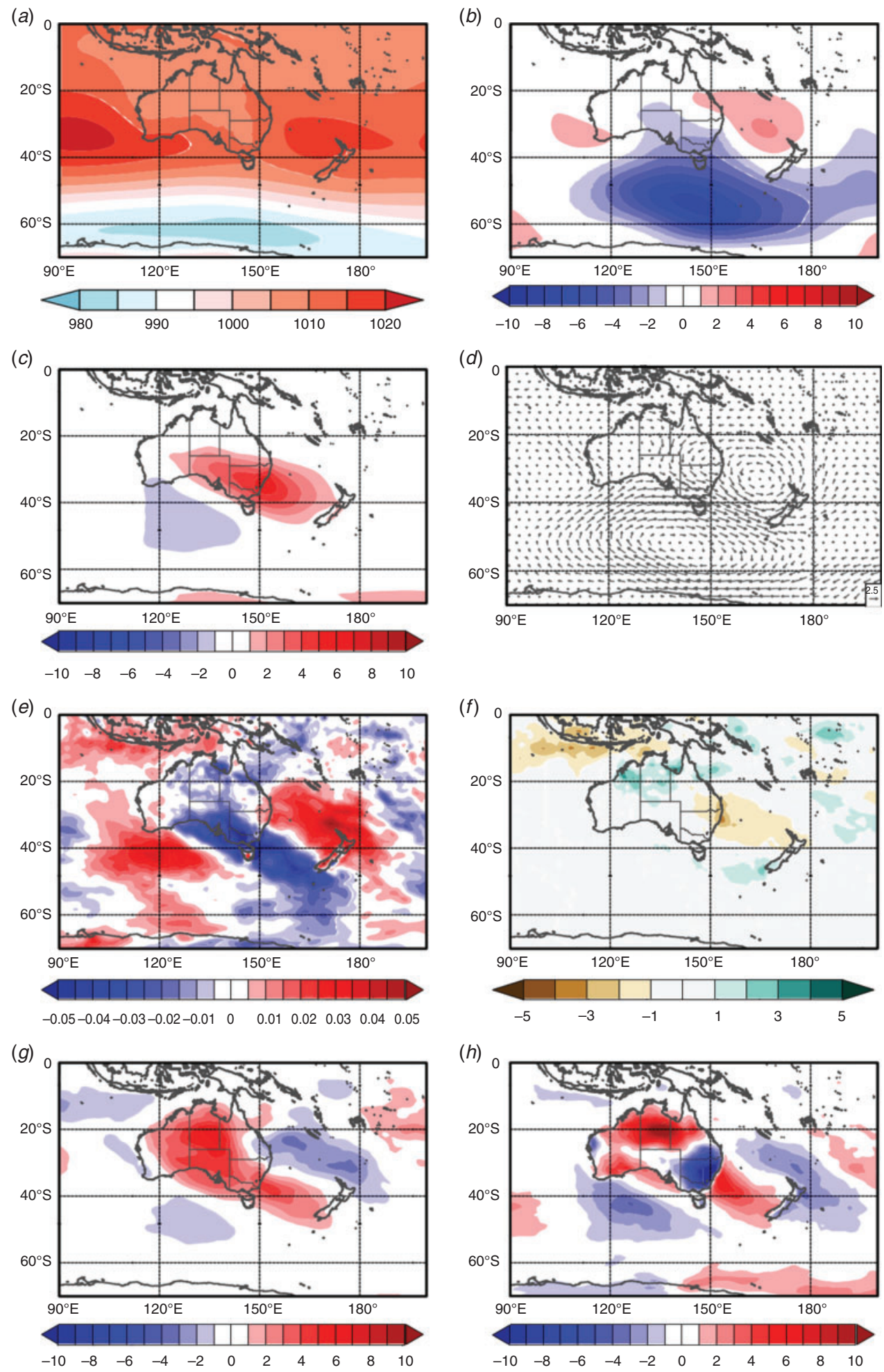

Fig. 5 Composite mean for all Sydney-area heatwave days. (a) Mean sea-level pressure (MSLP) (hPa). (b) MSLP anomalies (hPa). (c) 850-hPa temperature anomalies (K). (d) 850-hPa wind speed anomalies and wind vectors (reference wind vector at bottom right of the panel). (e) 500-hPa vertical motion $\omega$ anomalies $\left(\mathrm{Pa} \mathrm{s}^{-1}\right)$. $(f)$ Global Precipitation Climatology Project (GPCP) precipitation anomalies $\left(\mathrm{mm} \mathrm{day}^{-1}\right)$. $(g)$ Precipitable water anomalies $\left(\mathrm{kg} \mathrm{m}^{-2}\right)$. (h) 1000-hPa relative humidity anomalies (\%). 
(a)

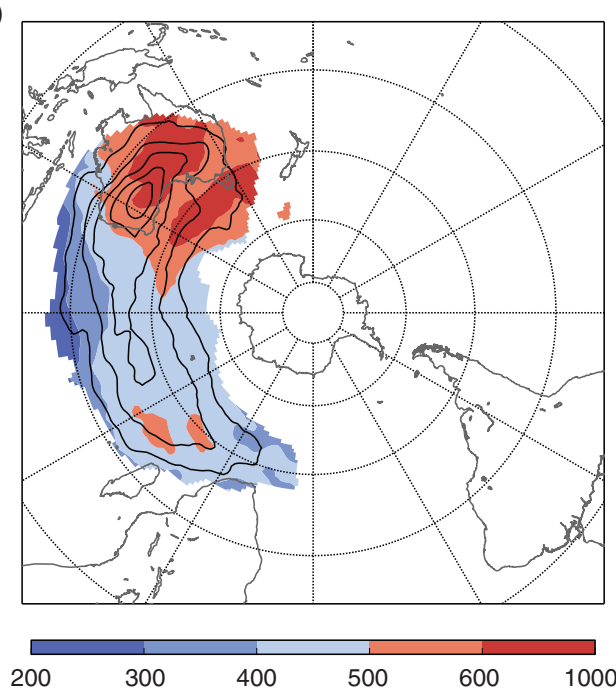

(b)
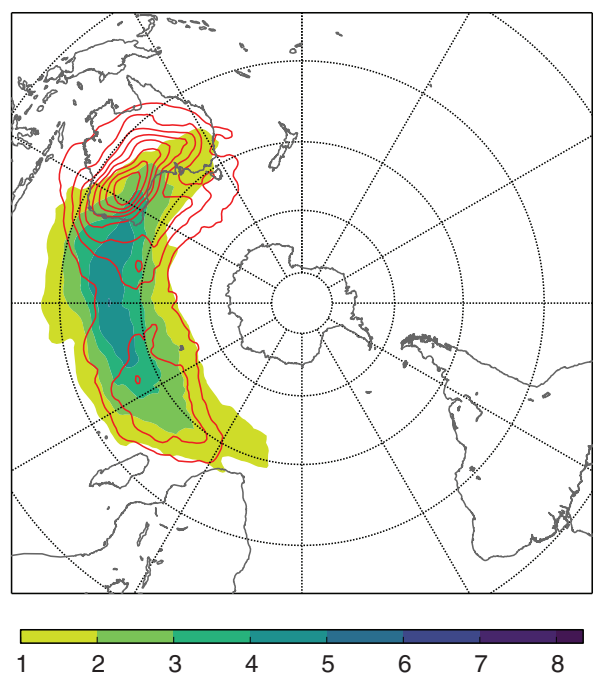

(c)

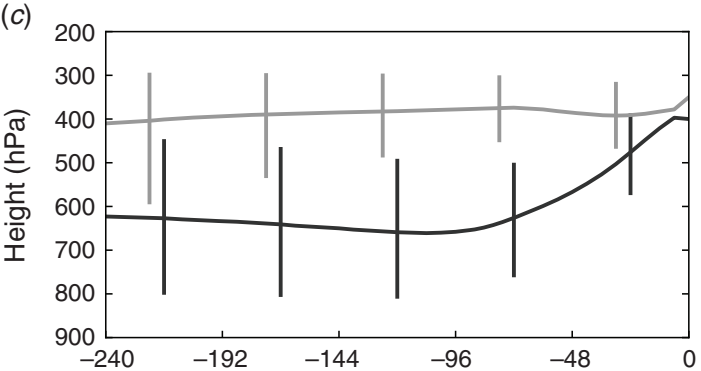

(e)

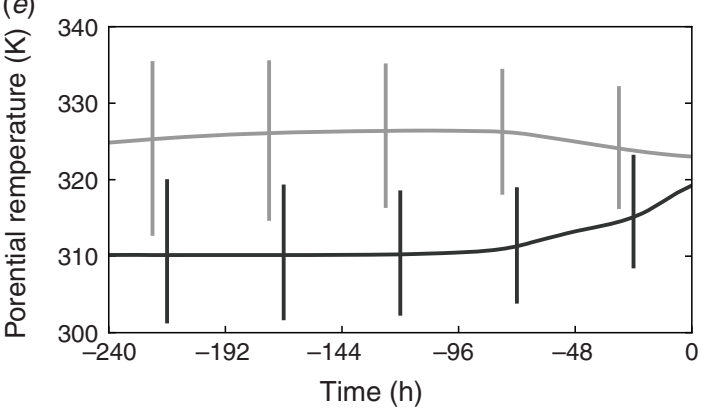

(d)

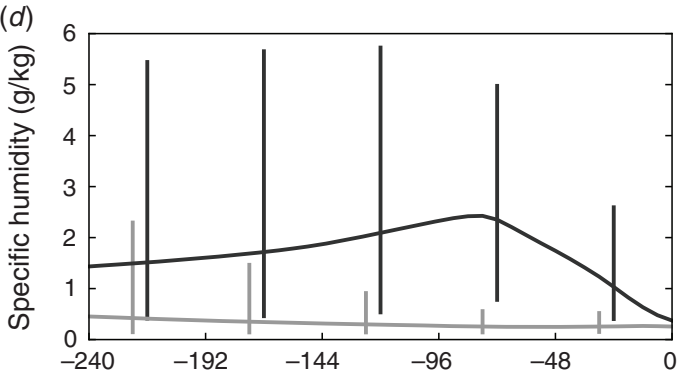

(f)

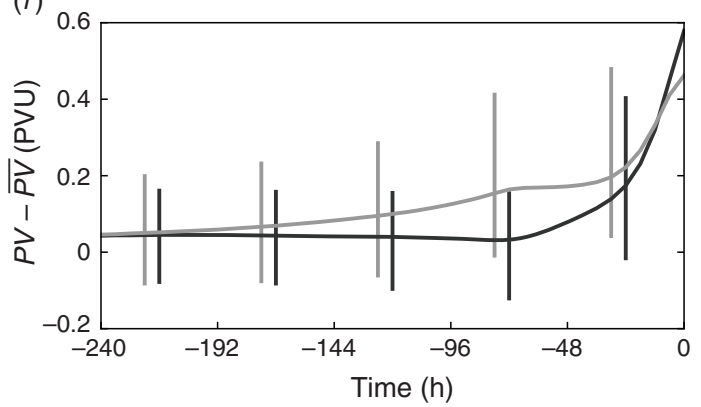

Fig. 6 (a) Mean height (shading in hPa) and spatial density (black contours every $\% 10^{-6} \mathrm{~km}^{-2}$ ) of trajectories that are involved in the formation of upper tropospheric anticyclones during Sydney heatwaves at $-72 \mathrm{~h}$. (b) Spatial densities of heatwave trajectories that are heated (cooled) between -72 and $0 \mathrm{~h}$ in red contours (shading) every $\% 10^{-6} \mathrm{~km}^{-2}$ at $-72 \mathrm{~h}$. Temporal evolution of $(c)$ height, $(d)$ specific humidity, $(e)$ potential temperature and $(f)$ potential vorticity $(\mathrm{PV})$ anomaly from the climatological mean along heatwave trajectories that are heated (cooled) between -72 and $0 \mathrm{~h}$ in black (grey). Whiskers mark the interquartile range.

in Section 2.3) are calculated and their spatial density at $-72 \mathrm{~h}$ is plotted in Fig. $6 a$. Three days prior to the heatwave, the air parcels that will constitute the upper-tropospheric anticyclonic PV anomaly lie in a band between southern Africa and eastern Australia bounded roughly between 10 and $55^{\circ} \mathrm{S}$. The maximum in the spatial density lies over south-western Australia. At this time, the air parcels to the east of the maximum are located in the lower half of the troposphere between 1000 and $600 \mathrm{hPa}$, the parcels to the west of the maximum lie in the middle troposphere between 600 and $400 \mathrm{hPa}$, and those to the north-west of the maximum and closest to the tropics lie above $400 \mathrm{hPa}$. Over the next $72 \mathrm{~h}$, the parcels located in the lower troposphere must ascend to reach the upper-tropospheric anticyclonic PV anomaly, whereas the altitudes of the parcels located in the middle and upper levels change relatively little. Although not shown here, 2 days later at $-24 \mathrm{~h}$, the highest parcel density is in the middle troposphere, centred just to the south of the continent over the Great Australian Bight. 
The relative roles of adiabatic and diabatic processes on the air parcels that constitute the upper anticyclone are considered now. The change in the potential temperature in the final $72 \mathrm{~h}$ of the parcel trajectories is $\Delta \theta$ and is a measure of the net diabatic heating or cooling of the parcel. Trajectories are grouped according to whether parcels are heated or cooled in the final $72 \mathrm{~h}$. The spatial density of these two groups at $-72 \mathrm{~h}$ is plotted in Fig. $6 b$. At this time, the parcels that are heated in the final $72 \mathrm{~h}$ lie preferentially over south-western Australia (Fig. 6b), more or less coincident with the maximum in the spatial density of all parcels (Fig. 6a). Presumably, these parcels are heated through condensation or freezing as they ascend to form the upper tropospheric anticyclonic PV anomaly. A second weaker maximum lies over the western Indian Ocean. In contrast, those parcels that are cooled lie preferentially to the west of Australia over the Indian Ocean. These parcels lie predominantly in the middle troposphere (Fig. 6b) and, therefore, ascend little. Presumably these parcels are cooled radiatively as they are advected from over the Indian Ocean into the uppertropospheric anticyclonic PV anomaly over the Sydney area.

Figure $6 c-f$ quantifies the changes in the pressure altitude, the specific humidity, the potential temperature and $P V-\overline{P V}$. Here $\overline{P V}$ is the climatological monthly mean of the $\mathrm{PV}$, and $P V-\overline{P V}$ is the PV anomaly of the parcel from the climatological mean at $-72 \mathrm{~h}$. As the PV anomaly is calculated relative to the climatological mean, it reflects both changes in the position of the parcel (mostly the meridional change) and diabatic heating or cooling. The mean changes as a function of time are plotted along with the interquartile range.

Consider first the parcels that are heated. In the mean, these parcels subside by less than $50 \mathrm{hPa}$ between about -240 and $-96 \mathrm{~h}$ before ascending from about 600 to $400 \mathrm{hPa}$ (Fig. $6 c$ ). The parcels are moistened while subsiding (Fig. 6d). Once they begin their ascent, the specific humidity rapidly decreases as water vapour is converted to droplets and ice particles (Fig. $6 d$ ). The potential temperature remains almost constant between about -240 and $-96 \mathrm{~h}$ but increases sharply by almost $10 \mathrm{~K}$ in the final $96 \mathrm{~h}$ (Fig. 6e). Although not shown, the PV becomes more cyclonic along the parcel trajectories between -96 and $-72 \mathrm{~h}$, which is consistent with a generation of cyclonic PV below the level of maximum diabatic heating. Between -24 and $0 \mathrm{~h}$, anticyclonic PV is generated along the trajectories as they are now located above the level of the maximum heating. Importantly, the net change in the PV is close to zero, consistent with the arguments of Methven (2015). However, the PV anomaly (from climatological mean) increases dramatically as the parcels ascend and are heated (Fig. 6f). This dramatic increase in the anticyclonic PV anomaly is due to both horizontal and vertical displacements: in the horizontal, the parcels are displaced poleward into a region that would otherwise be relatively cyclonic and in the vertical the parcel ascent lifts the tropopause producing a local anticyclonic anomaly.

Consider now the parcels that are weakly cooled in the last $72 \mathrm{~h}$. These parcels remain at a relatively constant pressure (Fig. 6c), very slightly dry (Fig. $6 d$ ) and cool by less than $3 \mathrm{~K}$ in the final $96 \mathrm{~h}$ (Fig. 6e). Although not shown, the PV remains virtually unchanged along the parcel trajectories as the motion is almost adiabatic. From -240 to $-48 \mathrm{~h}$, the PV anomaly increases slowly as, on average, air parcels are advected along the jet and are slowly displaced poleward (Fig. 6f). The increase in the PV anomaly in the final $48 \mathrm{~h}$ is much more marked as the Rossby wave packet amplifies and the parcels are advected poleward more rapidly (not shown).

Back trajectories starting from the near surface within the Sydney area (as outlined in Section 2.3) are calculated, and their spatial density at -72 and $-24 \mathrm{~h}$ is plotted in Fig. $7 a, b$. Prior to the heatwaves, the parcels that become part of near surface air mass are located predominantly offshore to the east of the continent. Most of the parcels lie below $900 \mathrm{hPa}$ (Fig. 7a). Over the next $72 \mathrm{~h}$, the air parcels subside and aggregate around the Sydney area below $950 \mathrm{hPa}$ (Fig. $7 b$ ).

The pressure altitude, the potential temperature and temperature along the parcel trajectories are shown in Fig. $7 c-e$. The mean changes as a function of time are plotted along with the interquartile range. For 10 days, the parcels subside from a mean pressure of $770-950 \mathrm{hPa}$ (Fig. 7 c). From -240 to about $-72 \mathrm{~h}$, the potential temperature falls by $\sim 2 \mathrm{~K}$, due presumably to radiative cooling (Fig. 7d) and the temperature increases by about $15 \mathrm{~K}$ through adiabatic compression (Fig. $7 e$ ). In the final $72 \mathrm{~h}$, as the parcels approach the surface and are entrained into the boundary layer, the potential temperature and temperature increase by $5 \mathrm{~K}$ (Fig. $7 d, e$ ), presumably through surface sensible heating.

Following Quinting et al. (2018), the mean near-surface trajectories can be divided into three groups based on the change in potential temperature $(\Delta \theta)$ from -120 to $0 \mathrm{~h}$. Changes in potential temperature along the trajectories result from diabatic processes. The three groups comprise those trajectories for which $\Delta \theta$ is in the uppermost pentile (called strongly diabatic), those for which it is in the lowermost pentile (called weakly diabatic) and the remainder. In the case of heatwaves in the Brisbane region (Quinting et al. 2018), the trajectories for the strongly and weakly diabatic cases are very different (Fig. 8a). In the strongly diabatic case, the trajectories originate to the south-west behind a midlatitude cyclonic anomaly and cross the south-eastern continent before reaching Brisbane. In contrast, the trajectories in the weakly diabatic case originate over the Tasman Sea to the east, turning anticyclonically near the coast and reaching Brisbane from the north-west. For heatwaves in south-eastern Australia, here referred to as Melbourne heatwaves (Quinting and Reeder 2017), the geographical properties of the trajectories for the strongly and weakly diabatic cases are broadly, although not entirely, the same (Fig. 8c). The trajectories originate over the ocean to the south of the Australian continent before turning anticyclonically over the south-east of Australia and approaching Melbourne from the north. For heatwaves in the Sydney region, the geographical differences between the trajectories for the strongly and weakly diabatic cases are more similar to those for Brisbane heatwaves than for Melbourne heatwaves, although not as marked (Fig. $8 b$ ). For the strongly diabatic case, many air parcels have a continental trajectory and reach Sydney from the west, similar to those for the strongly diabatic trajectories for Brisbane. Some trajectories in this class, however, are more similar to that of the weakly diabatic cases, which originate over the ocean to the south and east of the continent and turn anticyclonically before reaching Sydney from the north and north-west. 
(a) $\quad t=-72 \mathrm{~h}$
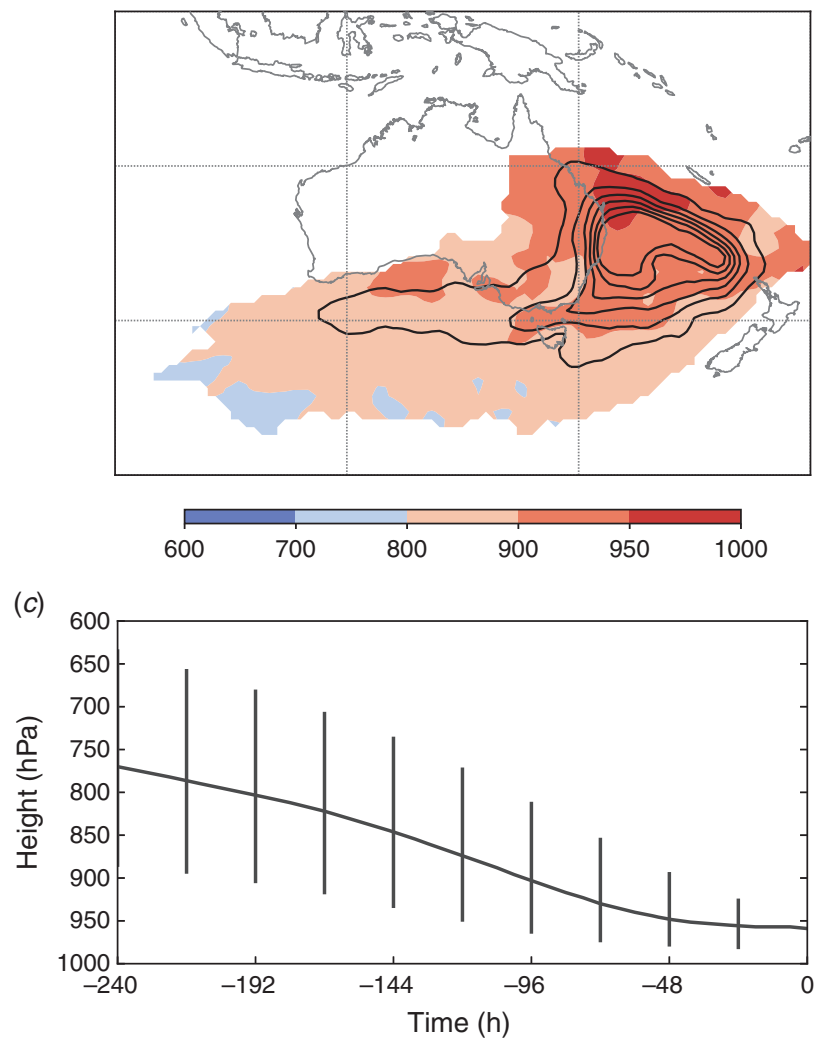

(b) $\quad t=-24 \mathrm{~h}$
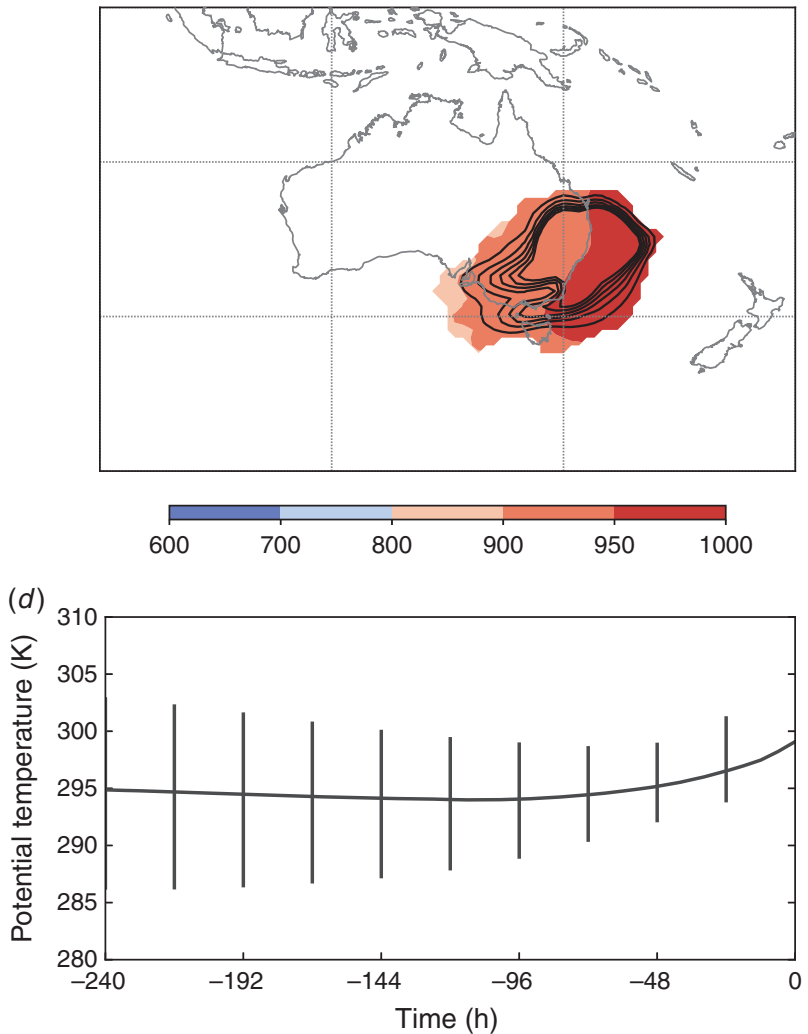

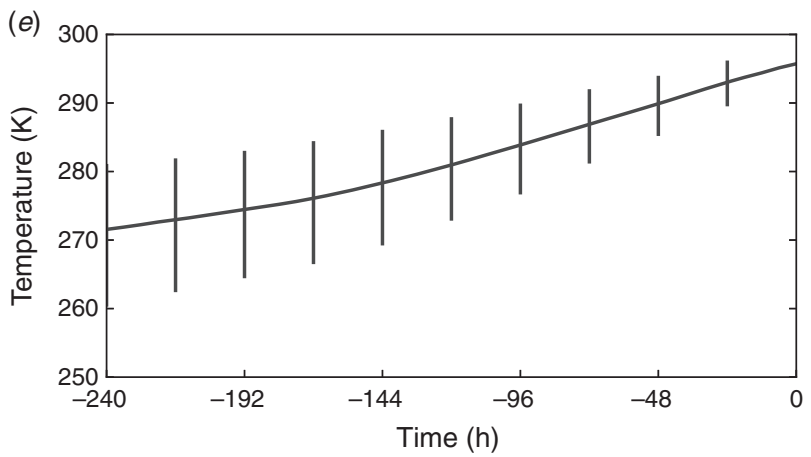

Fig. 7 Mean height (shading in hPa) and spatial density (black contours every $\% 10^{-6} \mathrm{~km}^{-2}$ ) of trajectories that arrive close to the surface at (a) $-72 \mathrm{~h}$ and $(b)-24 \mathrm{~h}$. Contour levels are $4,8,12,16,20,24 \% 10^{-6} \mathrm{~km}^{-2}$. Temporal evolution of $(c)$ height, $(d)$ potential temperature and (e) temperature along trajectories that arrive close to the surface. Whiskers mark the interquartile range.

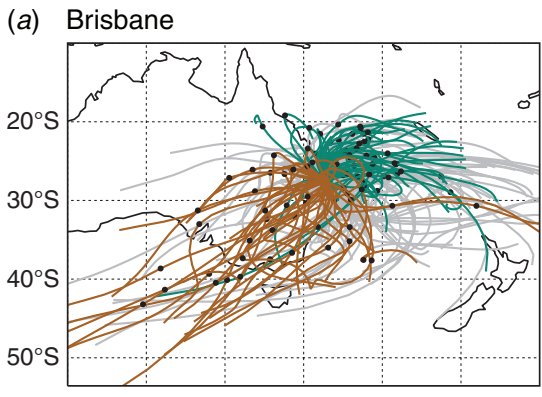

$130^{\circ} \mathrm{E} 140^{\circ} \mathrm{E} 150^{\circ} \mathrm{E} 160^{\circ} \mathrm{E} 170^{\circ} \mathrm{E}$

\section{(b) Sydney}

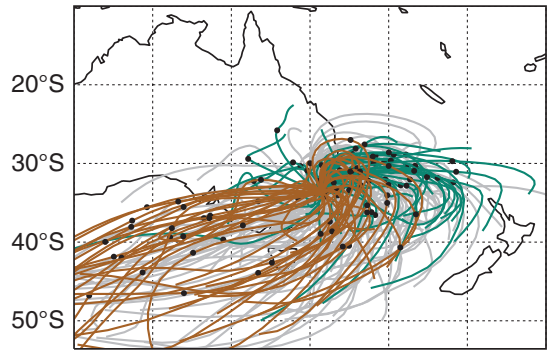

$130^{\circ} \mathrm{E} 140^{\circ} \mathrm{E} 150^{\circ} \mathrm{E} 160^{\circ} \mathrm{E} 170^{\circ} \mathrm{E}$

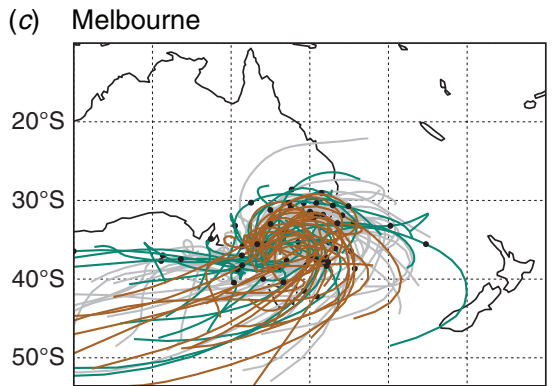

$130^{\circ} \mathrm{E} 140^{\circ} \mathrm{E} 150^{\circ} \mathrm{E} 160^{\circ} \mathrm{E} 170^{\circ} \mathrm{E}$

Fig. 8 Geographical distribution of the mean trajectories for the strongly diabatic (brown), weakly diabatic (green) and remaining (grey) groups of trajectories for each heatwave day from -120 to $0 \mathrm{~h}$ for the (a) Brisbane, (b) Sydney and (c) Melbourne regions. Black dots mark the location at $-60 \mathrm{~h}$. 
Thus, for Melbourne heatwaves, the near-surface air parcels have a maritime trajectory, originating in the westerlies over the ocean to the south of the continent. Although similar to the strongly diabatic case for Brisbane heatwaves, the parcels in that case have a long south-westerly trajectory over the heated continent. Melbourne heatwaves are more similar to the weakly diabatic case for Brisbane, in that the air parcels turn anticyclonically around a ridge over the Tasman Sea, before subsiding and warming adiabatically. For Sydney heatwaves, the strongly diabatic case includes air parcels which have a long continental trajectory and reach Sydney from the west, similar to the strongly diabatic case for Brisbane. However, some strongly diabatic trajectories, and the weakly diabatic case, are more similar to the weakly diabatic case for Brisbane, turning anticyclonically to reach Sydney from the north. There is a clear progression from heatwaves in Melbourne, where the trajectories are geographically very similar for both the strongly and weakly diabatic cases, to Brisbane, where the two cases are clearly geographically very distinct, with Sydney lying somewhere between the two.

\section{Conclusions}

The synoptic structure and evolution of summer heatwaves in the Sydney region was investigated through composite analyses and trajectory analysis. The investigation was motivated by the record-breaking heatwaves that affected southern Queensland, NSW and parts of northern Victoria in early 2017.

At upper tropospheric levels, Sydney-region heatwaves composites were characterised by an isolated anticyclonic PV anomaly to the south-east of Australia, flanked by cyclonic anomalies to the east and south. These PV anomalies extended through the upper part of the troposphere, with their maximum amplitudes near the tropopause.

A set of 10-day back trajectories was started from within the upper-tropospheric anticyclonic PV anomaly on the first day of the Sydney-region heatwave. This set was divided into two groups, the first group comprising those parcels that were weakly diabatically cooled in the final $72 \mathrm{~h}$ of their trajectory and the second being those parcels that were diabatically heated in the final $72 \mathrm{~h}$. The weak cooling was thought to be radiative and the heating thought to be due to phase changes in water. The change in the potential temperature of the parcels that cool was less than $3 \mathrm{~K}$ and so their motion was almost adiabatic. These parcels changed pressure altitude relatively little (less than $50 \mathrm{hPa}$ in the mean) and came predominantly from the upstream middle troposphere over the Indian Ocean. The change in the potential temperature of the parcels that were heated in the final $72 \mathrm{~h}$ is $10 \mathrm{~K}$ in the mean and up to $20 \mathrm{~K}$ for individual trajectories. At $-72 \mathrm{~h}$, these parcels lay predominantly in the lower half of the troposphere over the south-western part of the continent. They subsequently ascended about $200 \mathrm{hPa}$ on average and the specific humidity rapidly decreased and water was precipitated. These results suggested that the upper-tropospheric anticyclone, which was an essential dynamical feature of Sydney-region heatwaves, may be amplified by convection over the southwestern part of the continent, which in turn is favoured when the lower troposphere there is relatively moist.
The composite structure of Sydney-region heatwaves at low levels comprised a weak anticyclone over the east coast of Australia, centred in the Tasman Sea between NSW and New Zealand, with a broad region of low pressure further south over the Southern Ocean. This anticyclonic-cyclonic couplet directed anomalous, warm north-westerlies over the Sydney area, south-eastern Australia and the southern Tasman Sea. These north-westerlies from the continent were directed over the Sydney area and the associated subsidence resulted in anomalously low rainfall. Further afield, low-level wind anomalies were westerly in tropical north-west Australia, consistent with an active phase of the Australian monsoon, and were associated with the enhanced rainfall over the north of the continent. As shown by Parker et al. $(2013,2014)$ for heatwaves in Victoria, convection in the tropics may lead to enhancement of the upper level anticyclone either indirectly, through perturbation of the wave guide and subsequent wave amplification, or directly, through material advection of low-PV air from regions of moist convective outflow.

A set of 10-day low-level back trajectories was started from within a $500 \times 500 \mathrm{~km}$ box near the surface in the Sydney area on the first day of the heatwave. Five days prior to the heatwave, the parcels that become part of the near surface air mass were located predominantly offshore to the east and south of the continent. From -240 to about $-72 \mathrm{~h}$, the potential temperature fell by about $2 \mathrm{~K}$, due presumably to radiative cooling and the temperature rose by about $15 \mathrm{~K}$ through adiabatic compression. In the final $72 \mathrm{~h}$, the parcels were forced to descend, which is consistent with the downward deflection of the isentropes beneath the anticyclone. As the parcels approached the surface and were entrained into the boundary layer, the potential temperature and temperature increased by $5 \mathrm{~K}$, presumably through surface sensible heating. This result suggested that the elevated surface temperatures in a Sydney-region heatwave may be sensitive to the lower-tropospheric temperatures over the waters to the east and south of the continent and to the surface sensible heating in the neighbourhood of the Sydney area.

The upper-tropospheric structure differs between strongly and weakly diabatic heatwaves in the Sydney region (not shown). Strongly diabatic heatwaves are characterised by a midlatitude cyclonic PV anomaly to the south-east of the continent, flanked by a weaker anticyclonic PV anomaly to the north-east. The PV structure of weakly diabatic heatwaves is characterised by an upper-tropospheric anticyclonic anomaly centred over the Tasman Sea close to the Sydney region, with a horseshoe of anomalously cyclonic PV to the south and east. These two synoptic structures are very similar to the strongly and weakly diabatic heatwaves in the Brisbane region, and as a result, the trajectories of air parcels joining the near-surface air mass during a heatwave are geographically different, as is seen in Brisbane heatwaves (Quinting et al. 2018). However, the trajectories are not as distinct in the case of Sydney heatwaves, with some strongly diabatic cases resembling the Brisbane case, having long continental trajectories from the west, whereas other strongly diabatic cases are more similar to the weakly diabatic case for Sydney, with trajectories which originate over the ocean to the south and east of the continent and turn anticyclonically before reaching Sydney from the north and 
north-west. The trajectories with a maritime origin are more similar to the weakly diabatic Brisbane cases. In contrast, heatwaves in the Melbourne region (Quinting and Reeder 2017) do not show geographically distinct trajectories for the strongly and weakly diabatic cases, with all trajectories having a maritime origin to the south before turning anticyclonically to approach Melbourne from the North. In this respect, the trajectories for Melbourne heatwaves more closely resemble the weakly diabatic Brisbane cases. There is, thus, a clear progression from geographically distinct trajectories for the strongly and weakly diabatic cases in Brisbane heatwaves, to very similar trajectories for both cases in Melbourne heatwaves, with Sydney falling somewhere between the two.

In Section 1 the two questions were posed: how dynamically different are heatwaves in NSW from those in Victoria, and how representative was the heatwave of 9-12 February 2017 of previous heatwaves in NSW? The short answers are as follows: not much and highly representative.

In broad terms, the synoptic structure of the heatwave of 9-12 February was close to the composite mean of all heatwaves in the Sydney area. Moreover, although not shown, the other three heatwaves in early 2017 (9-13 January, 29 January-1 February and 4-6 February) were equally (perhaps more) similar to the composite mean. The principal difference between the individual heatwaves of early 2017 and the composite mean was that their amplitudes are larger, which is unsurprising as compositing smooths the fields. Heatwaves in the Sydney and Victoria regions have a great deal in common: both feature an upper anticyclone; air parcel trajectories that turn around this anticyclone and descend over the ocean; and convection in the tropics, which may enhance the upper anticyclone. The main dynamical differences between heatwaves in the Sydney area and those in Victoria are that the former are associated with relatively weak anticyclones in the Tasman Sea in conjunction with relatively strong cyclones south of the continent, whereas for the latter, it is the opposite.

\section{Acknowledgements}

MJR gratefully acknowledges funding provided by the Australian Research Council Centre of Excellence for Climate Extremes (CE170100023). Computer time for the trajectory calculations was provided by Australia's National Computational Infrastructure. The authors are grateful to Kevin Tory and an anonymous reviewer whose insightful comments helped to improve the presentation of our results.

\section{References}

Alexander, L. V., and Arblaster, J. M. (2009). Assessing trends in observed and modelled climate extremes over Australia in relation to future projections. Int. J. Climatol. 29, 417-435. doi:10.1002/JOC.1730

Bieli, M., Pfahl, S., and Wernli, H. (2015). A Lagrangian investigation of hot and cold temperature extremes in Europe. Q. J. R. Meteor. Soc. 141, 98-108. doi:10.1002/QJ.2339

Bureau of Meteorology (2017a). Special Climate Statement 60 - Exceptional Heat in Southeast Australia in Early 2017. pp. 1-15. Available at http://www.bom.gov.au/climate/current/statements/scs60.pdf [Verified 11 May 2020].

Bureau of Meteorology (2017b). Special Climate Statement 61 - Heavy Rainfall and Flooding in Southwest Western Australia. pp. 1-40.
Available at http://www.bom.gov.au/climate/current/statements/scs61. pdf [Verified 11 May 2020].

Coates, L., Haynes, K., O’Brien, J., McAneney, J., and De Oliveira, F. D. (2014). Exploring 167 years of vulnerability: an examination of extreme heat events in Australia 1844-2010. Environ. Sci. Policy 42, 33-44. doi:10.1016/J.ENVSCI.2014.05.003

Cowan, T., Purich, A., Perkins, S., Pezza, A., Boschat, G., and Sadler, K. (2014). More frequent, longer, and hotter heat waves for Australia in the Twenty-First Century. J. Clim. 27, 5851-5871. doi:10.1175/JCLI-D-1400092.1

Dee, D. P., Uppala, S. M., Simmons, A. J., Berrisford, P., Poli, P., Kobayashi, S., Andrae, U., Balmaseda, M. A., Balsamo, G., Bauer, P., Bechtold, P., Beljaars, A. C. M., van de Berg, L., Bidlot, J., Bormann, N., Delsol, C., Dragani, R., Fuentes, M., Geer, A. J., Haimberger, L., Healy, S. B., Hersbach, H., Hólm, E. V., Isaksen, L., Källberg, P., Köhler, M., Matricardi, M., McNally, A. P., Monge-Sanz, B. M., Morcrette, J.-J., Park, B.-K., Peubey, C., de Rosnay, P., Tavolato, C., Thépaut, J. -N., and Vitart, F. (2011). The ERA-Interim reanalysis: configuration and performance of the data assimilation system. Q.J.R. Meteor. Soc. 137, $553-$ 597. doi:10.1002/QJ.828

Gibson, P. B., Pitman, A. J., Lorenz, R., and Perkins-Kirkpatick, S. E. (2017). The role of circulation and land surface conditions in current and future Australian heat waves. J. Clim. 30, 9933-9948. doi:10.1175/ JCLI-D-17-0265.1

Herold, N., Kala, J., and Alexander, L. V. (2016). The influence of soil moisture deficits on Australian heatwaves. Environ. Res. Lett. 11, 1-8. doi:10.1088/1748-9326/11/6/064003

Hoskins, B. J., McIntyre, M. E., and Robertson, A. W. (1985). On the use and significance of isentropic potential vorticity maps. Q. J. R. Meteor. Soc. 111, 877-946. doi:10.1002/QJ.49711147002

Huffman, G. J., Adler, R. F., Morrissey, M. M., Bolvin, D. T., Curtis, S., Joyce, R., McGavock, B., and Susskind, J. (2001). Global precipitation at one-degree daily resolution from multi-satellite observations. J. Hydrometeor. 2, 36-50. doi:10.1175/1525-7541(2001)002<0036: GPAODD $>2.0 \mathrm{CO} ; 2$

Kala, J., Evans, J. P., and Pitman, A. J. (2015). Influence of antecedent soil moisture conditions on the synoptic meteorology of the Black Saturday bushfire event in southeast Australia. Q. J. R. Meteor. Soc. 141, 31183129. doi:10.1002/QJ.2596

McIntyre, M. E., and Palmer, T. N. (1983). Breaking planetary waves in the stratosphere. Nature 305, 593-600. doi:10.1038/305593A0

McIntyre, M. E., and Palmer, T. N. (1984). The "surf zone" in the stratosphere. J. Atmos. Terr. Phys. 46, 825-849. doi:10.1016/00219169(84)90063-1

Meehl, G. A., and Tebaldi, C. (2004). More intense, more frequent, and longer lasting heat waves in the 21 st century. Science 305, 994-997. doi:10.1126/SCIENCE.1098704

Methven, J. (2015). Potential vorticity in warm conveyor belt outflow. Q. J. R. Meteor. Soc. 141, 1065-1071. doi:10.1002/QJ.2393

O'Brien, L., and Reeder, M. J. (2017). Southern Hemisphere summertime Rossby waves and weather in the Australian region. Q. J. R. Meteor. Soc. 143, 2374-238. doi:10.1002/QJ.3090

Parker, T. J., Berry, G. J., and Reeder, M. J. (2013). The influence of tropical cyclones on heat waves in Southeastern Australia. Geophys. Res. Lett. 40, 6264-6270. doi:10.1002/2013GL058257

Parker, T. J., Berry, G. J., and Reeder, M. J. (2014). The structure and evolution of heat waves in Southeastern Australia. J. Clim. 27, 57685785. doi:10.1175/JCLI-D-13-00740.1

Perkins, S. E., and Alexander, L. V. (2013). On the measurement of heat waves. J. Clim. 26, 4500-4517. doi:10.1175/JCLI-D-12-00383.1

Perkins, S. E., Argüeso, D., and White, C. J. (2015). Relationships between climate variability, soil moisture, and Australian heatwaves. J. Geophys. Res. Atmos. 120, 8144-8164. doi:10.1002/2015JD023592 
Pfahl, S., Schwierz, C., Croci-Maspoli, M., Grams, C. M., and Wernli, H. (2015). Importance of latent heat release in ascending air streams for atmospheric blocking. Nat. Geosci. 8, 610-614. doi:10.1038/ NGEO2487

Purich, A., Cowan, T., Cai, W., van Rensch, P., Uotila, P., Pezza, A. B., Boschat, G., and Perkins, S. (2014). Atmospheric and oceanic conditions associated with Southern Australian heat waves: A CMIP5 analysis. Clim. Dyn. 27, 7807-7829. doi:10.1175/JCLI-D-14-00098.1

Quinting, J. F., and Reeder, M. J. (2017). Southeastern Australian heat waves from a trajectory viewpoint. Mon. Wea. Rev. 145, 4109-4125. doi:10. 1175/MWR-D-17-0165.1
Quinting, J. F., Parker, T. J., and Reeder, M. J. (2018). Two synoptic routes to subtropical heat waves as illustrated in the Brisbane region of Australia. Geophys. Res. Lett. 45, 10700-10708. doi:10.1029/2018GL079261

Song, J., Li, C., Pan, J., and Zhou, W. (2011). Climatology of anticyclonic and cyclonic Rossby wave breaking on the dynamical tropopause in the Southern Hemisphere. J. Clim. 24, 1239-1251. doi:10.1175/ 2010JCLI3157.1

Sprenger, M., and Wernli, H. (2015). The LAGRANTO Lagrangian analysis tool - version 2.0. Geosci. Model Dev. 8, 2569-2586. doi:10.5194/ GMD-8-2569-2015 